\title{
DESENVOLVIMENTO DA CONSCIÊNCIA METATEXTUAL SOBRE A ESTRUTURA TÓPICA DO PARÁGRAFO
}

\section{DEVELOPMENT OF METATEXTUAL AWARENESS ABOUT THE TOPICAL STRUCTURE OF THE PARAGRAPH}

\author{
Marcus Vinicius Brotto de Almeida*
}

\begin{abstract}
Resumo: A organização tópica é um fenômeno integrante do conhecimento linguístico relacionado à distribuição das informações num texto. O principal objetivo desta pesquisa é oferecer uma abordagem didática para desenvolver a consciência metatextual nos alunos sobre a estrutura tópica do parágrafo argumentativo. Para alcançar esse objetivo, inicialmente, produziu-se uma unidade didática com atividades baseadas em operações metalinguísticas - identificação dos parâmetros, comparação entre estruturas bem e malformadas, produção e correção de falhas (GERHARDT, 2016) - e fornecimento de conhecimento metaestratégico relacionado aos processos da escrita. Em seguida, aplicou-se o material a alunos, para verificar o efeito da unidade didática na percepção da organização tópica, na produção textual e na experiência de usar a metodologia na sala de aula. Concluiu-se que a eficácia da unidade didática não pôde ser avaliada devido ao desengajamento dos alunos para realizar as operações metalinguísticas e empregar as estratégias de composição. A despeito desse desengajamento, argumentase que o desenvolvimento metacognitivo e metalinguístico deve ser implantado desde o início da vida escolar, pois se apresenta como uma proposta de ensino de língua focada no processo capaz de substituir $o$ atual ensino de língua centrado no produto.
\end{abstract}

Palavras-chave: Estrutura tópica. Parágrafo. Desenvolvimento metalinguístico. Escrita. Ensino.

\begin{abstract}
The topical organization phenomenon is part of the person's linguistic knowledge related to the distribution of information in a text. The main goal of this research is to offer a didactic approach about the metatextual awareness development on students related to the topical structure of the argumentative paragraph. To reach this goal, at first, we produced a teaching material with activities based on metalinguistic processes - identification of parameters, comparison between good and bad written structures, production, and correction of mistakes (GERHARDT, 2016) - and also with information about metaestrategic knowledge related to written processes. After that, this material was used by students, due to check the effect of didatic unit on the students' perception of the topical organization, on their text production and on experience of using the proposed methodology in classroom. We conclude that the efficiency of the didactic material could not be assessed because of the students' disengagement to perform the metalinguistic operations and to apply writing strategies. Despite this disengagement, it is argued that metacognitive and metalinguistic development should be implemented from the beginning of school life, since it corresponds to a language teaching proposal focused on the process capable of replacing the current language teaching centered on the product.
\end{abstract}

Keywords: Topical structure. Paragraph. Metalinguistic development. Writing. Teaching.

\section{Introdução}

Frequentemente os professores enfrentam dificuldade para tratar das falhas relacionadas à desorganização das informações nos textos produzidos pelos alunos, pois

\footnotetext{
* Doutor em Letras Vernáculas (Língua Portuguesa). Professor de Língua Portuguesa no Instituto Federal de Educação, Ciência e Tecnologia do Rio de Janeiro. Integrante do grupo de pesquisa Educação Linguística na Rede Técnica e Tecnológica (ELITE). E-mail: marcus.almeida@ifrj.edu.br
} 
os livros didáticos de língua portuguesa, apesar de abordarem frequentemente a estrutura composicional dos gêneros textuais, raramente discutem como se distribuem as informações de um texto, fenômeno relevante para a construção da coerência. $O$ rótulo "desorganização das ideias" recobre uma série de fenômenos, como baixa informatividade, falta de articulação e sequenciação inadequada das informações. Já há bastante literatura produzida que diagnostica esses e outros problemas de escrita em ambiente escolar (Cf. VAL, 1999; PÉCORA, 1999 [1983]). O foco desta investigação será propor um caminho para abordar didaticamente tais falhas.

Na Linguística, a discussão acerca da organização das informações de um texto pode ser feita por meio do conceito de tópico discursivo (LAUTAMATTI, 1978; BROWN; YULE, 1983). Emprega-se frequentemente a metáfora da "espinha dorsal" para representar a estrutura responsável pela distribuição das informações, ou seja, a hierarquização e a sequenciação de tópicos e subtópicos nos textos. Devido à restrição imposta pela linearidade da produção linguística, não se pode dizer tudo de uma só vez. Por essa razão, o tópico principal é esmiuçado em subtópicos mais específicos, que formam uma sequência de grupamentos tópicos. Dooley e Levinsohn (2001) apresentam uma motivação cognitiva para que as coisas sejam assim:

\footnotetext{
Por que os textos não podem simplesmente vir como sequências uniformes de sentenças? Uma resposta é sugerida pelos princípios gerais da cognição. Os humanos tipicamente processam grandes quantidades de informação em PEDAÇOS, assim como comemos uma refeição em mordidas. Isto nos ajuda a lidar com a complexidade [...]. Em um discurso mais longo, realmente haverá muitos itens de informação; o falante divide o material em partes que podem ser tratadas separadamente. O que agrupamentos temáticos de sentenças refletem, então, é partição conceptual (DOOLEY; LEVINSOHN, 2001, p. 36, grifo no original, tradução nossa).
}

Assim, a estrutura tópica de um texto lida com o encadeamento desses grupamentos temáticos. É por essa razão que a estrutura tópica e a paragrafação costumam estar intimamente relacionadas (LIBERATO; FULGÊNCIO, 2007; GOUTSOS, 1997). A paragrafação, portanto, revela bastante acerca de como o autor dividiu o tópico e hierarquizou os subtópicos.

Mais do que um mero recurso tipológico dos textos escritos, o parágrafo representa uma unidade informacional. A organização tópica do parágrafo é um fenômeno integrante do conhecimento linguístico dos redatores e leitores proficientes, que é acionado na produção e compreensão dos textos. Os leitores utilizam esse conhecimento para identificar quais tópicos são centrais e quais são periféricos e para avaliar se um texto está completo e bem formado (GOMBERT, 1992; SPINILLO; SIMÕES, 2003; FERREIRA; SPINILLO; SIMÕES, 2003; SPINILLO, 2009).

O redator pouco experiente, não obstante, pode incorrer em falha ao cumprir os requisitos da organização tópica do parágrafo, uma vez que ela concerne ao domínio de uma norma ligada às práticas de letramento. A seguinte redação, produzida a partir da proposta "Leis e penas mais duras são a única solução para o trânsito brasileiro?", formulada pelo Banco de Redações UOL, ilustra a falha na organização tópica no nível do parágrafo:

As fabricas estão entupindo o Brasil com 3 milhões de carros por ano. Como vai ser daqui a dez anos???? Uma grande porcentagem destas pessoa que compraram seu primeiro carro não sabem nem de que lado 
sentar nele imagina dirigir. Não se tem educação no transito. Só multas que é o que interessa para o governo. Se o governo estivesse interessado nas mortes não deixaria centenas de pessoas morrerem nas filas do SUS pelo Brasil a fora. E tem mais: A alguns dias estava no DETRAN esperando para fazer exame de vista e comecei a assistir a prova de estacionamento. Teve uma pessoa que levou uns 10 minutos para estacionar o carro. E deve ter saído de La com a carteira.

Agora ele chega no centro e leva dez minutos para estacionar o carro e quem estiver atrás de vai ter que esperar. Eu acho o fim da picada. A lei tem que mudar. Não pode ficar multando só que ultrapassa a velocidade mas sim tomar a carteira de quem atrapalha no transito. Três multas por esse motivo e esta sem carteira. E esse governo que ai esta em vez de sumir com todo o dinheiro dos impostos deveria urgentemente começar a fazer estradas de ferro para tirar esse absurdo de caminhões que temos nas estradas hoje atrapalhando o transito, encarecendo as mercadorias, provocando acidentes e estragando todas as estradas. E começar também a implementar estradas novas pois se continuar desse jeito logo o pais vai estar parado. Outro absurdo: pedágio. Pedágio quem tem que pagar são os caminhões pois são eles que destroem as estradas.

É isso ai...

Disponível em: <http://educacao.uol.com.br/bancoderedacoes/redacao/ult4657u156.jh tm>. Acesso em: 30 ago. 2015.

A organização tópica desse texto não corresponde ao padrão esperado para o gênero "redação dissertativa". Embora todo o texto se refira a problemas relacionados ao trânsito, não é possível identificar, nos seus parágrafos, o "ponto em debate" em torno do qual as informações se congreguem e que funcione como um elemento estruturador e unificador. Os textos escritos formais normalmente exibem elevado grau de exigência com relação à organização tópica. Contrariando essa expectativa, essa redação exibe uma estrutura tópica que parece bastante influenciada pelo registro empregado nas interações orais informais (EGGINS, 2004; GERHARDT, 2015). Tratase do modelo de composição que Scardamalia e Bereiter (1986) batizaram de relato de conhecimento, em que o redator redige o que sabe sobre o assunto, geralmente numa associação linear, em que o conteúdo da frase anterior engatilha o conteúdo da frase seguinte e, assim, sucessivamente até que o conhecimento sobre o tema esteja esgotado.

As falhas de organização tópica em parágrafos estão relacionadas a um insuficiente letramento linguístico (RAVID; TOLCHINSKY, 2002) e à dificuldade para desempenhar o papel de "redator" numa situação comunicativa caracterizada por elevado grau de formalidade e pelo distanciamento temporal entre o momento de produção e o de recepção, o que exige que o texto escrito materialize linguisticamente o seu contexto.

A noção de papel de redator põe em evidência a natureza processual da escrita. As abordagens cognitivistas têm descrito a escrita como uma atividade complexa, que exige a realização de inúmeros processos mentais necessários ao planejamento, à produção e à revisão textuais. Além disso, o redator precisa lidar com inúmeras restrições que condicionam a produção, como o contexto sócio-histórico-cultural, o domínio da língua e do código escrito, a imagem que deseja construir, o leitor pretendido, os limites do gênero textual a ser produzido, o tempo de que dispõe para escrever e as condições materiais do contexto imediato de produção, como a 
possibilidade de uso de programas computacionais editores de texto, consulta a fontes etc. (HAYES, 1996)

É por esse motivo que esses estudos têm destacado o papel da metacognição na escrita proficiente. De modo sucinto, a metacognição consiste na atividade cognitiva que atua sobre a própria cognição (FLAVELL, 1979; SCHWARTZ; PERFECT, 2002; Van OVERSCHELDE, 2008; METCALFE, 2008), estando presente na habilidade para monitorar e regular os processos cognitivos realizados durante a escrita (HACKER; KEENER; KIRCHER, 2009; SITKO, 1998). Parte dessa atividade metacognitiva se volta para a linguagem. Esse fenômeno, denominado consciência metalinguística, está relacionado à percepção da língua como uma estrutura analisável e manipulável e ao monitoramento e à regulação do uso linguístico (GOMBERT, 1992).

A partir das inúmeras dificuldades em escrita enfrentadas pelos estudantes, convém meditar sobre a responsabilidade do ensino de língua em relação ao insuficiente desenvolvimento do letramento linguístico dos alunos. Pode-se argumentar que essa deficiência decorra de um ensino centrado no conteúdo, mas alheio à pessoa do aprendiz (GERHARDT, 2013), o que pode ser observado pelo ensino voltado para o texto como produto, mas indiferente ao processo da escrita e da aprendizagem da escrita (PEREIRA, 2017). Em decorrência disso, observa-se um ensino de escrita que sistematicamente desconsidera o desenvolvimento das habilidades e meta-habilidades implicadas na composição proficiente.

Como a organização tópica do parágrafo não costuma ser sistematicamente abordada nos livros didático, professores e alunos dispõem de poucos materiais para tratar desse tipo de estrutura textual e suas falhas. Embora surjam da intenção do professor de ajudar, as indicações genéricas e imprecisas, como "a redação carece de coerência", "parágrafo confuso" ou "redação com ideias desorganizadas", têm pouco a contribuir para o amadurecimento dos estudantes, pois não lhes permitem perceber objetivamente as falhas estruturais do texto e, consequentemente, não lhes possibilitam adotar medidas corretivas. É preciso ter ferramentas conceituais e metodológicas para fazer com que tais falhas de estruturação ocupem o primeiro plano da atenção do aprendiz.

Partindo dessas ponderações e assumindo o pressuposto de que é possível aprimorar a consciência linguística no nível textual (SPINILLO; SIMÕES, 2003; SPINILLO, 2009), propôs-se a seguinte questão motivadora para a investigação: como desenvolver a consciência metatextual sobre a organização tópica do parágrafo argumentativo em estudantes do ensino médio? Para responder a essa indagação, uma unidade didática, formada por conhecimento teórico e atividades práticas, foi elaborada e aplicada a uma turma regular do ensino médio.

Considerando-se o problema posto, o principal objetivo desta pesquisa consiste em analisar o impacto da unidade didática na consciência metalinguística sobre a estrutura tópica do parágrafo por meio do exame de textos produzidos pelos estudantes.

Após essa introdução, a próxima seção aborda o conceito de estrutura tópica adotado na unidade didática; em seguida, a partir de uma perspectiva cognitivista, discute-se a relação entre o processo da escrita, a metacognição e a consciência metalinguística; posteriormente, apresenta-se a metodologia empregada na pesquisa; depois, apresentam-se e discutem-se os resultados; encerra-se com as considerações finais. 


\section{Estrutura tópica do parágrafo}

O modelo de estrutura tópica do parágrafo adotado na unidade didática segue o modelo já descrito em manuais de redação, como demonstram as noções de "tópico frasal" (GARCIA, 2004 [1967]), "frase-núcleo" (SOARES; CAMPOS, 1978) e "período tópico" (FIGUEIREDO, 1999). Também contribuiu para a formulação da unidade didática o conceito de "periodicidade", que, adotando a perspectiva sistêmicofuncional, diz respeito às categorias funcionais responsáveis por demarcar o fluxo de informações num texto, considerando-se a sua crescente complexidade estrutural (MARTIN; ROSE, 2007).

O modelo de estrutura tópica descreve a distribuição das informações do parágrafo, considerando-se o status informacional de uma proposição em relação às demais. Essa estrutura é formada por quatro categorias funcionais, como pode ser observado na seguinte Fig. 1, onde os parênteses indicam os elementos que podem ser omitidos:

Fig. 1: Estrutura tópica do parágrafo

$\left.\begin{array}{c}\text { (Período } \\ \text { contextualizador) }\end{array}\right\rangle$ Período tópico $\left.\left.\>\begin{array}{c}\text { Períodos de } \\ \text { expansão }\end{array}\right\rangle \begin{array}{c}\text { (Período de } \\ \text { conclusão) }\end{array}\right\rangle$

O período tópico enuncia o ponto em debate no parágrafo. Como o hipertema de Martin e Rose, (2007) e o tópico frasal de Garcia (2004 [1967]), o período tópico tem natureza preditiva, ao explicitar o objetivo do parágrafo e dar indício de como a expansão aprofundará o tópico. Como a redação argumentativa se caracteriza pela defesa de uma opinião, é natural que o período tópico de cada parágrafo se refira a uma faceta dessa tese. O período tópico pode ser precedido por um período contextualizador, que pode cumprir várias funções, como fornecer informação prévia sobre o tópico, defini-lo, apresentar uma anedota ou um fato histórico relacionado a ele e fazer a passagem do tópico do parágrafo anterior para o tópico do parágrafo atual.

Os períodos de expansão são responsáveis por desenvolver e aprofundar o tópico (Cf. o "desenvolvimento" de GARCIA, 2004 [1967]). A fase de expansão é caracterizada pela exposição dos argumentos que a justificam ou sustentam, por meio da apresentação de explicações, provas, detalhes, comparações, declarações de especialistas e exemplos relacionados ao período tópico. A expansão pode ser finalizada por um período de conclusão decorrente do que foi apresentado no parágrafo. À semelhança do conceito de hipernovo de Martin e Rose (2007), o período de conclusão tem natureza retrospectiva e expressa uma ideia a que se pode chegar com base na argumentação apresentada. A conclusão também pode cumprir a função de fazer a passagem do tópico do parágrafo atual para o tópico do parágrafo seguinte.

Como já se disse, o desenvolvimento da consciência metalinguística está relacionado à capacidade para conceber a língua como uma estrutura. Na unidade didática, a organização do parágrafo foi descrita com base na adaptação dos seguintes parâmetros propostos por Gerhardt (2016) para a observação da estrutura sintática: (i) a presença dos elementos constituintes (tópico e expansão); (ii) a congruência da relação estabelecida entre os elementos constituintes; (iii) a fronteira entre os elementos; e (iv) a ordem de aparição dos elementos.

A partir dos parâmetros de observação da organização tópica do parágrafo, estabeleceu-se a seguinte sistematização das falhas e das operações de edição para corrigi-las, conforme mostra a Tab. 1 abaixo: 
Tab. 1: Sistematização dos parâmetros, falhas e operações de edição

\begin{tabular}{|l|l|l|}
\hline \multicolumn{1}{|c|}{ Parâmetros } & \multicolumn{1}{|c|}{ Falhas } & \multicolumn{1}{c|}{ Operações de edição } \\
\hline \multirow{4}{*}{$\begin{array}{l}\text { 1. Elementos constituintes: } \\
\text { presença e congruência }\end{array}$} & $\begin{array}{l}\text { Ausência ou má formulação } \\
\text { do tópico }\end{array}$ & $\begin{array}{l}\text { Adição ou reformulaço do } \\
\text { tópico }\end{array}$ \\
\cline { 2 - 3 } & $\begin{array}{l}\text { Ausência ou inconsistência } \\
\text { da expansão }\end{array}$ & $\begin{array}{l}\text { Adição ou reformulação da } \\
\text { expansão }\end{array}$ \\
\cline { 2 - 3 } & $\begin{array}{l}\text { Incongruência entre os } \\
\text { elementos constituintes }\end{array}$ & $\begin{array}{l}\text { Adição, supressão ou } \\
\text { reformulação do conteúdo }\end{array}$ \\
\hline \multirow{4}{*}{$\begin{array}{l}\text { 2. Fronteira entre os } \\
\text { constituintes }\end{array}$} & $\begin{array}{l}\text { Delimitação incorreta entre } \\
\text { tópico e expansão }\end{array}$ & $\begin{array}{l}\text { Adição de pontuação } \\
\text { correta }\end{array}$ \\
\cline { 2 - 3 } & $\begin{array}{l}\text { Fragmentação do grupo } \\
\text { tópico-expansão }\end{array}$ & Deslocamento de texto \\
\cline { 2 - 3 } Acúmulo de tópicos & Deslocamento de texto \\
\hline \multirow{2}{*}{ 3. Ordem dos constituintes } & $\begin{array}{l}\text { Posicionamento incorreto } \\
\text { dos constituintes }\end{array}$ & $\begin{array}{l}\text { Deslocamento dos } \\
\text { constituintes }\end{array}$ \\
\hline
\end{tabular}

Tendo sido abordada a organização tópica do parágrafo, a próxima seção discutirá o gerenciamento metacognitivo sobre os processos da escrita.

\section{Escrita, metacognição e consciência metalinguística}

Desde a década de 1980, as pesquisas cognitivistas têm demonstrado que a escrita é uma atividade complexa que envolve a realização de inúmeros processos cognitivos recorrentes e concomitantes, tais como estabelecer objetivos, traçar planos, selecionar e organizar conteúdo, transformar pensamento em texto escrito, avaliar e editar (HAYES; FLOWER, 1980; HAYES, 1996; SCARDAMALIA; BEREITER, 1986; KELLOGG, 1994; TORRANCE; GALBRAITH, 2006; HACKER; KEENER; KIRCHER, 2009; MacARTHUR; GRAHAM, 2016). Mais recentemente, as pesquisas cognitivistas têm destacado a relevância dos aspectos motivacionais e afetivos implicados na escrita (ZIMMERMAN; RISEMBERG, 1997; ZIMMERMAN; KITSANTAS, 2007; HIDI; BOSCOLO, 2009; BRUNING; KAUFFMAN, 2016).

Dadas as demandas cognitivas da atividade e as limitações da memória humana (McCUTCHEN; TESKE; BANKSTON, 2008; TORRANCE; GALBRAITH, 2006), as abordagens cognitivistas frequentemente abarcam o componente metacognitivo associado à escrita. A metacognição concerne aos conhecimentos metacognitivos - que abrangem as crenças sobre o funcionamento da mente e os conhecimentos sobre as tarefas, as estratégias e as condições necessárias para usar esses conhecimentos - e à capacidade para regular (i.e., planejar, monitorar e controlar) a própria atividade cognitiva (FLAVELL, 1979; NELSON; NARENS, 1990, 1994; Van OVERSCHELDE, 2008; METCALFE, 2008).

Os modelos cognitivistas costumam abarcar a dimensão metacognitiva porque compreendem que a escrita habilidosa envolve o conhecimento metacognitivo relacionado à composição e a regulação intencional dos processos de composição, como estabelecer objetivos e planos de escrita, empregar estratégias e avaliar e ajustar as ações. Para Hacker, Keener e Kircher (2009), por exemplo, os processos de ler, reler, refletir e rever consistem em processos de monitoramento, que garantem que a produção de significado está em conformidade com os objetivos estabelecidos pelo autor para o texto, ao passo que editar, elaborar, gerar ideias, produzir texto e reformular correspondem a estratégias de controle responsáveis pela efetiva produção de 
significado. O nível de desenvolvimento metacognitivo tem sido apontado como a principal característica que distingue os redatores maduros dos inexperientes: "os escritores experientes são mais metacognitivamente conscientes, tomando mais decisões sobre planejamento e monitoramento e avaliando mais enquanto escrevem" (McCORMICK, 2003, p. 88, tradução própria).

Parte dessa atividade metacognitiva aplicada à escrita se volta para o uso linguístico. $\mathrm{Na}$ perspectiva da Psicolinguística, a consciência metalinguística corresponde à meta-habilidade especificamente centrada na linguagem por dizer respeito à capacidade para conceber a língua como uma estrutura autônoma dos contextos específicos de uso e passível de ser analisada e para monitorar e regular os processos cognitivos relacionados à produção e à compreensão de linguagem (GOMBERT, 1992; CAMPS; MILIAN, 2000). Por essa razão, a capacidade metalinguística consiste numa atividade genuinamente metacognitiva, intencional e reflexiva sobre a linguagem, estando, portanto, disponível para verbalização. O reconhecimento da consciência metalinguística tem implicações importantes para o ensino de língua por estar estreitamente relacionada ao aprendizado do letramento (GOMBERT, 1992; RAVID; TOLCHINSKY, 2002). A reflexão metalinguística se subdivide em diferentes tipos em decorrência do estrato linguístico tomado como foco de atenção deliberada: conhecimento metafonológico, metamorfológico, metassintático, metalexical, metassemântico, metapragmático e metatextual (GOMBERT, 1992). A manipulação da organização tópica é uma habilidade metatextual ligada ao monitoramento e à regulação da distribuição das informações de um texto, empregada pelas pessoas letradas durante o estabelecimento da coerência tanto na produção quanto na compreensão.

A próxima seção trata da metodologia empregada na pesquisa.

\section{Metodologia}

A realização da pesquisa abrangeu a formulação de uma unidade didática (UD), cujo objetivo era estimular o desenvolvimento da consciência metatextual sobre a organização tópica do parágrafo argumentativo; a confecção de dois instrumentos para a coleta de dados (análise de parágrafos e produção de redação argumentativa); a aplicação desse material a uma turma do ensino médio; e a análise do impacto da UD na percepção da estrutura tópica do parágrafo pelos aprendizes.

$\mathrm{Na}$ fase experimental, o material foi aplicado a uma turma de $2 .^{\circ}$ ano do ensino médio, formada por 13 alunos com idade entre 16 e 17 anos, durante um curso de extensão com 16 aulas. A instituição era uma ONG, que fornecia assistência social e educacional a jovens e famílias residentes em comunidades socialmente vulneráveis situadas na Zona Sul do Rio de Janeiro.

A UD foi formulada de maneira que o aprendiz (i) conceptualizasse a organização tópica como um fenômeno linguístico que pode ser observado na estruturação do parágrafo; (ii) empregasse estratégias para facilitar ou potencializar a realização dos processos de planejamento, produção e revisão da estruturação tópica dos parágrafos; (iii) identificasse as falhas relativas a essa estruturação, considerando as convenções formais do gênero textual; e (iv) fosse capaz de manipular deliberadamente a organização tópica.

A UD foi organizada em duas partes. A primeira, de natureza descritiva e teórica, fornecia definições e conceitos para a construção do conhecimento declarativo sobre argumentação, processos da escrita e organização tópica do parágrafo 
argumentativo. A segunda parte consistia numa sequência de atividades escolares que orientavam a realização de operações metalinguísticas sobre a estrutura tópica.

$\mathrm{Na}$ confecção da unidade didática, adaptou-se, para a abordagem da organização tópica do parágrafo argumentativo, a seguinte sequência de operações metalinguísticas sistematizada por Gerhardt (2016) para estimular a percepção de fenômenos da estruturação sintática por aprendizes: (i) atividades de reconhecimento do fenômeno linguístico estudado (as partes que o formam e os seus parâmetros de constituição); (ii) atividades de comparação entre estruturas bem e malformadas; (iii) atividades de identificação e correção de falhas na construção; e (iv) atividades de produção da estrutura. Essas operações metalinguísticas foram articuladas aos principais processos cognitivos da escrita, fornecendo-se conhecimento procedimental sobre como planejar, produzir e revisar a estrutura tópica de parágrafos por meio da instrução explícita de estratégias, a fim de evitar a sobrecarga na memória de trabalho dos aprendizes.

Como eram objetivos do trabalho comprovar as hipóteses de que a UD é capaz de aprimorar a consciência metatextual sobre a organização tópica e, consequentemente, de que tal conhecimento metalinguístico refletiria no melhoramento da realização dessa estrutura nas produções dos alunos, foram utilizados dois instrumentos de coleta de dados para aferir o impacto da intervenção: a análise da organização tópica de parágrafos e a produção de redação argumentativa. Ambos foram aplicados no início da intervenção e reaplicados ao seu término.

Um dos instrumentos de coleta de dados consistia na produção de análises contrastivas acerca da organização e do desenvolvimento das informações em dois parágrafos, sendo um bem estruturado e o outro mal estruturado. Essas produções analíticas visavam a verificar a possível mudança na qualidade da reflexão metalinguística, já que uma das principais características decorrentes da natureza deliberada e intencional da atividade metalinguística é a capacidade de verbalização (GOMBERT, 1992).

A primeira análise, realizada antes da intervenção, tinha o objetivo de mapear o conhecimento prévio dos estudantes sobre a organização tópica. A segunda análise, produzida ao fim do curso, tinha o objetivo de captar a mudança na capacidade dos informantes de externar a reflexão metatextual após a exposição à UD. Caso a segunda análise apresentasse justificativas mais consistentes e explícitas acerca da estruturação tópica para fundamentar a análise, a hipótese de que a UD é capaz de aprimorar o conhecimento metatextual dos alunos estaria confirmada. A seguir, apresenta-se um exemplo da tarefa: 
Compare estes parágrafos argumentativos sobre o tema "Violência contra a mulher: por que o machismo persiste?" proposto pelo site Brasil Escola. Em seguida, faça uma análise quanto à organização e ao desenvolvimento das informações nesses parágrafos.

\begin{tabular}{|c|c|}
\hline PARÁGRAFO 1 & PARÁGRAFO 2 \\
\hline $\begin{array}{l}\text { Os recursos das mídias } \\
\text { também trazem todos os sentidos } \\
\text { das comunicações e informações } \\
\text { movidas pela globalização e a } \\
\text { idealização machista, como por } \\
\text { exemplo, as propagandas, que } \\
\text { passam à sociedade a ilustração } \\
\text { feminina como uma ferramenta } \\
\text { corpórea, sensual e imoral. O } \\
\text { senso religioso não escapa da } \\
\text { polêmica, durante a Idade Média, } \\
\text { na relação sexual entre um casal, } \\
\text { dizia a Igreja Católica que de } \\
\text { forma alguma a mulher poderia } \\
\text { sentir prazer no ato, não fazendo } \\
\text { isto ela era encaminhada ao fogo } \\
\text { da santa inquisição, } \\
\text { menosprezando todos os direitos } \\
\text { humanos, especialmente a } \\
\text { liberdade assim como a vida. } \\
\text { Portanto, a moralidade e a } \\
\text { consciência de que a mulher não } \\
\text { é mais apenas uma dona de casa } \\
\text { têm que vir de casa, dos pais } \\
\text { passando aos filhos, para que a } \\
\text { sociedade vá mudando cada vez } \\
\text { mais esse pensamento machista } \\
\text { de ser. } \\
\text { http://vestibular.brasilescola.uol.com.br/banco }\end{array}$ & $\begin{array}{l}\text { Influências culturais são } \\
\text { determinantes para a grande } \\
\text { recorrência de crimes como o } \\
\text { estupro e a violência doméstica. É } \\
\text { evidente que essas influências são } \\
\text { transmitidas de geração para } \\
\text { geração de maneira espontânea, } \\
\text { porém a falta de discussão e } \\
\text { debate sobre o machismo em } \\
\text { instituições de ensino, por } \\
\text { exemplo, dificulta a superação de } \\
\text { costumes considerados causa de } \\
\text { um problema que precisa ser } \\
\text { combatido, a fim de proporcionar } \\
\text { evolução nas relações humanas. } \\
\text { Por se tratar, muitas vezes, de } \\
\text { crimes de ordem sexual, ainda } \\
\text { considerados tabus, como o } \\
\text { estupro, grande parte das escolas } \\
\text { não aborda estatísticas, forma de } \\
\text { prevenção e penalidades, o que } \\
\text { corrobora o aumento desse crime } \\
\text { entre crianças e adolescentes, que } \\
\text { ora são vítimas, ora agressores. } \\
\text { http://vestibular.brasilescola.uol.com.br/banco } \\
\text {-de-redacoes/10010/(adaptado) }\end{array}$ \\
\hline
\end{tabular}

A solicitação das análises foi formulada de modo a provocar a explicitação de uma reflexão metatextual, já que os estudantes deveriam analisar se a estrutura subjacente à organização e ao desenvolvimento das informações estava bem ou mal construída em cada parágrafo e justificar tal julgamento. Para tanto, não era necessário o uso de uma terminologia precisa e rigorosa. As análises produzidas pelos estudantes foram distribuídas em quatro categorias: (i) paráfrase do conteúdo (a análise não foca na estrutura tópica do parágrafo, mas apenas comenta seu conteúdo); (ii) atividade epilinguística ou reflexão metacomunicativa (a análise explicita avaliações quanto à facilidade ou dificuldade para compreender o parágrafo e quanto ao fato de os parágrafos estarem bem ou mal estruturados, mas não justifica essas impressões); (iii) mescla entre análise da estrutura e paráfrase do conteúdo; e (iv) atividade metatextual (a análise explicitamente foca a organização tópica do parágrafo).

O outro instrumento de coleta de dados consistia na aplicação de duas propostas de redação argumentativa formuladas pelo sítio "Brasil Escola", já que também era objetivo da pesquisa comprovar a hipótese de que a instrução que promove o desenvolvimento da consciência metatextual sobre a organização tópica tem efeito 
positivo sobre a qualidade do parágrafo. A primeira proposta, sobre o tema "Exposição nas redes sociais: há limites?", foi realizada antes da exposição à UD; e a segunda, sobre o tema "Desafios da educação no Brasil", ao fim do curso. Para avaliar as redações, foram atribuídas notas aos quesitos relacionados à organização tópica dos parágrafos, conforme mostra a Tab. 2 a seguir.

Tab. 2: Grade de avaliação da organização tópica do parágrafo

\begin{tabular}{|c|c|c|}
\hline & Parâmetros & Critérios de pontuação \\
\hline \multirow{3}{*}{$\begin{array}{l}\text { 1. Elementos } \\
\text { constituintes: } \\
\text { presença e } \\
\text { congruência }\end{array}$} & $\begin{array}{l}\text { Presença e } \\
\text { formulação do } \\
\text { tópico }\end{array}$ & $\begin{array}{l}2,0=\text { O tópico está presente e é bem formulado em todos os } \\
\text { parágrafos do texto. } \\
1,5=\text { A legibilidade do texto é ligeiramente comprometida pela } \\
\text { formulação do tópico de alguns parágrafos. } \\
1,0=\text { A ausência ou a má formulação do tópico afeta negativamente a } \\
\text { legibilidade dos parágrafos. } \\
0,5=\text { A legibilidade do texto é gravemente prejudicada pela ausência } \\
\text { ou má formulação do tópico de vários parágrafos. } \\
0=\text { A ausência ou a má formulação do tópico impede o entendimento } \\
\text { do texto. }\end{array}$ \\
\hline & $\begin{array}{l}\text { Presença e } \\
\text { consistência } \\
\text { da expansão }\end{array}$ & $\begin{array}{l}\text { 2,0 = Todos os tópicos apresentam expansão consistente. } \\
1,5=\text { Embora haja a expansão de todos os tópicos, ela nem sempre é } \\
\text { feita com profundidade. } \\
1,0=\text { A inconsistência da expansão de alguns tópicos afeta } \\
\text { negativamente a legibilidade do texto como um todo. } \\
0,5=\text { A maioria dos tópicos têm a legibilidade gravemente } \\
\text { prejudicada pela inconsistência da expansão. } \\
0=\text { A ausência ou inconsistência da expansão tornam todos os } \\
\text { tópicos pouco informativos. }\end{array}$ \\
\hline & $\begin{array}{l}\text { Congruência } \\
\text { entre os } \\
\text { elementos } \\
\text { constituintes }\end{array}$ & $\begin{array}{l}\text { 2,0 = A relação entre as proposições é congruente em todos os casos. } \\
\text { 1,5 = A relação entre as proposições é pouco clara em alguns pontos, } \\
\text { o que prejudica localmente a compreensão do texto. } \\
1,0=\text { A incongruência local prejudica a compreensão do texto como } \\
\text { um todo. } \\
\text { 0,5 = A incongruência entre as proposições é frequente e prejudica } \\
\text { gravemente a compreensão do texto. } \\
0=\text { A incongruência é sistemática e impede a compreensão do texto. }\end{array}$ \\
\hline \multirow{3}{*}{$\begin{array}{l}\text { 2. Fronteira } \\
\text { entre os } \\
\text { constituintes }\end{array}$} & $\begin{array}{l}\text { Delimitação } \\
\text { entre tópico e } \\
\text { expansão }\end{array}$ & $\begin{array}{l}1,0=\text { A delimitação entre tópico e comentário é corretamente } \\
\text { realizada em todos os casos. } \\
0,5=\text { A delimitação entre tópico e comentário está incorretamente } \\
\text { marcada em alguns casos. } \\
0=\text { A delimitação entre tópico e comentário é realizada } \\
\text { incorretamente com frequência. }\end{array}$ \\
\hline & $\begin{array}{l}\text { Integridade do } \\
\text { grupo tópico- } \\
\text { expansão }\end{array}$ & $\begin{array}{l}1,0=\text { Todos os parágrafos consistem numa unidade informacional, } \\
\text { formada por tópico e expansão. } \\
0,5=\text { Algumas unidades informacionais encontram-se fragmentadas } \\
\text { em diferentes parágrafos. } \\
0=\text { As unidades informacionais encontram-se sistematicamente } \\
\text { fragmentadas em parágrafos diversos. }\end{array}$ \\
\hline & $\begin{array}{l}\text { Unicidade } \\
\text { tópica }\end{array}$ & $\begin{array}{l}1,0=\text { Todos os parágrafos contêm um único tópico. } \\
0,5=\text { Alguns parágrafos apresentam mais de um tópico. } \\
0=\text { Diferentes tópicos encontram-se aglomerados em diversos } \\
\text { parágrafos. }\end{array}$ \\
\hline $\begin{array}{l}\text { 3. Ordem } \\
\text { dos } \\
\text { constituintes }\end{array}$ & $\begin{array}{l}\text { Ordem dos } \\
\text { constituintes }\end{array}$ & $\begin{array}{l}1,0=\text { Todos os parágrafos apresentam tópico e expansão } \\
\text { corretamente posicionados. } \\
0,5=\text { Poucos parágrafos apresentam tópico e expansão } \\
\text { incorretamente posicionados. } \\
0=\text { Diversos parágrafos apresentam tópico e expansão } \\
\text { incorretamente posicionados. }\end{array}$ \\
\hline
\end{tabular}


A realização dos três critérios relacionados à presença e à congruência dos elementos constituintes podia receber uma pontuação de 0 (zero) a 2,0 (dois) cada. Já os critérios relacionados ao estabelecimento de fronteira e à ordenação dos constituintes podiam receber uma pontuação entre 0 (zero) e 1,0 (um) cada. Assim, a pontuação total podia variar de 0 (zero) a 10,0 (dez). Optou-se por atribuir uma pontuação maior aos itens relacionados à presença e à congruência entre os elementos devido à sua interferência direta na coerência.

A próxima seção é dedicada à apresentação e discussão dos resultados obtidos por meio dos instrumentos de coleta de dados.

\section{Resultados e discussão}

A Tab. 3 a seguir contrasta a distribuição das análises contrastivas produzidas pelos alunos nas quatro categorias.

Tab. 3: Comparação dos resultados das análises contrastivas de parágrafos

\begin{tabular}{|l|c|c|}
\hline \multicolumn{1}{|c|}{ Categorias de resposta } & Pré-exposição & Pós-exposição \\
\hline Paráfrase do conteúdo epilinguística ou reflexão & $41,6 \%$ & $45,4 \%$ \\
\hline $\begin{array}{l}\text { Atividade } \\
\text { metacomunicativa }\end{array}$ & $25 \%$ & $36,3 \%$ \\
\hline $\begin{array}{l}\text { Mescla entre análise da estrutura e paráfrase do } \\
\text { conteúdo }\end{array}$ & $8,3 \%$ & - \\
\hline Atividade metatextual & $16,6 \%$ & $18,1 \%$ \\
\hline
\end{tabular}

Com base nos dados, é possível concluir que a capacidade de reflexão metatextual ou de explicitação apresentou ligeira elevação, de 1,5\%, após a intervenção.

O gráfico (Fig. 2) a seguir compara a pontuação atribuída à organização tópica dos parágrafos nas duas redações produzidas por cada estudante (os nomes são fictícios).

Fig. 2: Comparação entre as pontuações atribuídas nas duas produções

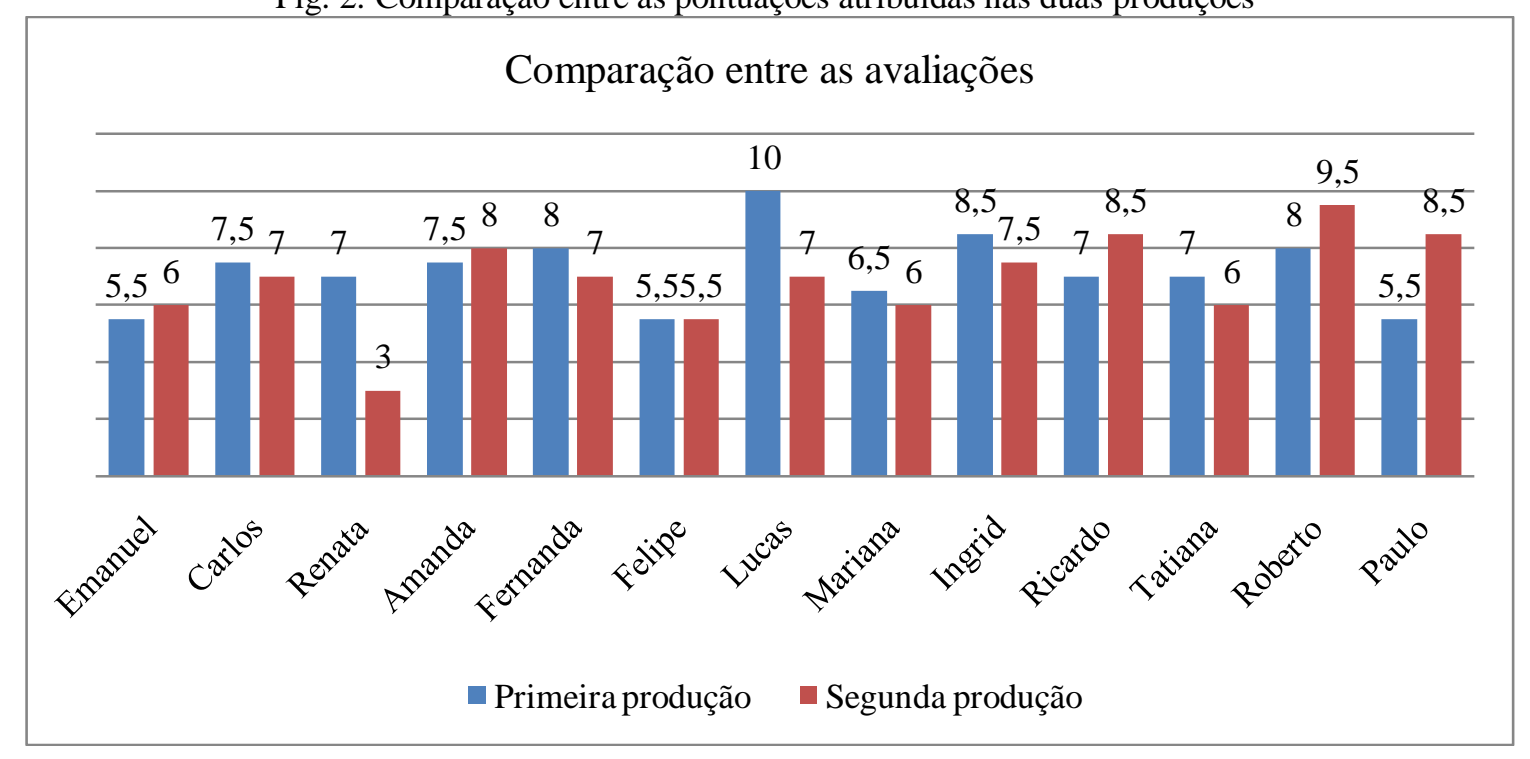


Uma das hipóteses estabelecidas nesta pesquisa consistia em considerar que, caso a pontuação atribuída à organização tópica da segunda produção superasse àquela atribuída à estrutura tópica da primeira redação, então isso seria um indício de que a UD é capaz de aprimorar a consciência metatextual. O próximo gráfico (Fig. 3) divide as redações da segunda produção em dois grupos: aquelas que receberam uma pontuação superior à da primeira e aquelas que receberam uma pontuação igual ou inferior à da primeira.

Fig. 3: Comparação do desempenho na segunda produção com o da primeira

Situação da segunda produção comparativamente com a da primeira

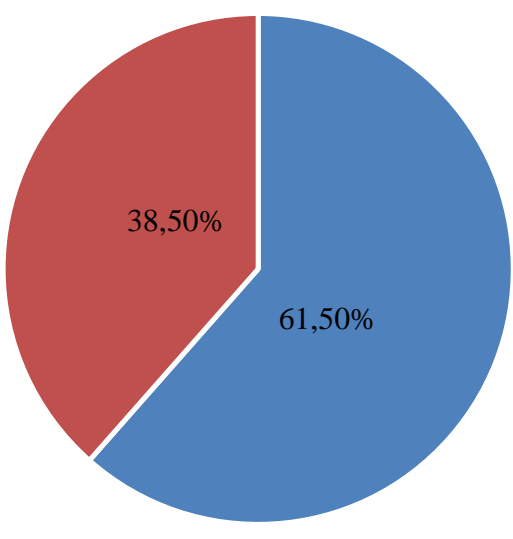

- A pontuação atribuída à segunda produção é inferior ou igual à da primeira redação

- A pontuação atribuída à segunda produção é superior à da primeira redação

Esse gráfico mostra que, em geral, o desempenho na segunda produção foi pior do que aquele observado na primeira redação, já que em apenas 38,5\% dos casos, a segunda composição recebeu uma pontuação superior à da primeira.

O objetivo geral desta pesquisa era investigar como o ensino de língua materna poderia propiciar o desenvolvimento da consciência metatextual sobre a organização tópica do parágrafo argumentativo. Para tanto, formulou-se uma unidade didática com atividades que orientavam a tomada de consciência dos parâmetros constituintes dessa estrutura linguística. Entre os objetivos específicos estavam: (i) avaliar a eficiência da UD em melhorar a percepção da estrutura tópica pelos estudantes; (ii) verificar o efeito dessa percepção na organização tópica dos parágrafos produzidos por eles; e (iii) refletir sobre a experiência e os desafios vividos durante a implantação desse tipo de metodologia de ensino de produção textual em sala de aula.

A comparação entre as duas análises contrastivas produzidas pelos estudantes revelou que não houve mudança significativa na capacidade de reflexão metatextual sobre a estrutura tópica do parágrafo. Na primeira análise (pré-exposição), 41,6\% das respostas apenas parafrasearam o conteúdo dos parágrafos, sem oferecer uma análise da organização das informações. Na segunda análise (pós-exposição), o percentual de paráfrases dos parágrafos subiu para 45,4\%. Quanto à presença de reflexão metatextual, $16,6 \%$ das respostas da primeira análise demonstraram alguma capacidade de analisar os parágrafos metatextualmente, ao passo que o percentual subiu para apenas $18,1 \%$ na segunda análise.

Além disso, apesar de as repostas que revelaram alguma reflexão metalinguística na segunda produção indicarem a capacidade de observar os parágrafos como uma estrutura autônoma analisável, elas foram tão genéricas que poderiam ter sido dadas mesmo se os alunos não tivessem sido expostos à UD. Assim, com base nos 
dados colhidos por esse instrumento, concluiu-se que os alunos não demonstraram um desenvolvimento significativo na capacidade de refletir metatextualmente sobre a organização tópica do parágrafo argumentativo.

Quanto à produção das redações argumentativas, a expectativa era que os parágrafos da segunda produção (pós-exposição) fossem mais organizados e mais completos quando comparados aos da primeira produção (pré-exposição), o que confirmaria a hipótese de que o aprimoramento da consciência metatextual tem um efeito positivo sobre a qualidade dos parágrafos produzidos. No entanto, o gráfico (Fig. 3) mostra que, em $61,5 \%$ dos casos, a segunda produção recebeu uma pontuação igual ou inferior à da primeira e que, em apenas 38,4\% dos casos, a segunda produção recebeu uma pontuação superior à da primeira.

A constatação de que não houve melhora significativa na capacidade de verbalizar a reflexão metalinguística e de que, em $61,5 \%$ dos casos, o desempenho na segunda produção não superou o da primeira parece indicar que a UD é ineficaz. Contudo, a observação do processo de aprendizagem durante a intervenção não sustenta essa conclusão inicial. É preciso considerar que os alunos apresentaram um engajamento insuficiente na realização das atividades propostas na UD, especialmente aquelas que exigiam a produção ou a reformulação de textos. Consequentemente, os alunos deixaram de realizar as operações de manipulação da estrutura dos parágrafos, cujo objetivo era desenvolver a consciência metatextual sobre a organização tópica. Assim, é possível conjeturar que o desempenho inferior na segunda produção seja um reflexo dessa falta de motivação para exercitar a escrita e, assim, pôr em prática as estratégias e os conhecimentos aprendidos nas aulas; conclui-se, portanto, que a parte experimental da pesquisa não atingiu o objetivo de averiguar a eficácia da UD.

Como diversos teóricos têm enfatizado, os fatores motivacionais e afetivos têm forte impacto no desempenho dos escritores e dos aprendizes. Entre os aspectos que influenciam negativamente, Zimmerman e Kitsantas (2007) destacam os seguintes:

Ambientes de escrita adversos, precárias práticas comportamentais de escrita, baixas percepções de autoeficácia ou dos benefícios do letramento podem prejudicar o engajamento nas atividades de escrita e o desenvolvimento subsequente da habilidade de letramento (ZIMMERMAN; KITSANTAS, 2007, p. 53, tradução nossa).

Os alunos demonstraram fraca motivação para realizar as atividades devido à baixa valorização atribuída às tarefas de escrita no ambiente escolar, que são vistas como desinteressantes e enfadonhas, e aos afetos negativos relacionados a esse fenômeno. Convém perceber que, ao longo do curso, as declarações dadas pelos alunos que mostraram desvalorização e insatisfação ligadas à escrita se referem apenas ao contexto de sala de aula, e não às situações de uso no ambiente familiar.

Três componentes são relevantes para entender a valoração atribuída pelos estudantes às tarefas no ambiente de aprendizagem: (i) a percepção do indivíduo sobre a importância da tarefa, que influencia na persistência para o cumprimento da tarefa; (ii) o seu interesse pessoal na tarefa, que está relacionado ao nível de envolvimento em termos de uso de estratégias cognitivas e ao desempenho real; e (iii) a sua percepção da utilidade da tarefa para ele próprio, tanto no contexto imediato quanto na vida profissional ou pessoal (PINTRICH, 2003).

Altos níveis de valoração da tarefa estão associados com resultados cognitivos adaptativo, como elevados níveis de uso de estratégias autorregulatórias e elevados níveis de realização bem-sucedida, o que revela a relação entre a valoração da tarefa e o 
engajamento cognitivo. Assim, os materiais didáticos devem ser significativos e interessantes para os estudantes para favorecer a valoração dos estudos. Quanto ao componente afetivo, o afeto influencia o uso de estratégias cognitivas, autorregulatórias e de raciocínio. $\mathrm{O}$ afeto positivo facilita a pré-disposição cognitiva para a realização de tarefas, ao passo que o afeto negativo conduz a uma postura aversiva ou evasiva e a uma maior intolerância às falhas. (PINTRICH, 2003).

O desempenho ruim dos alunos na segunda produção parece sinalizar que o desenvolvimento da consciência metatextual acerca da organização tópica do parágrafo argumentativo nos estudantes não é capaz de influenciar positivamente a qualidade da organização das informações dos parágrafos escritos por eles. Essa conclusão, contudo, também não é válida. A repercussão da reflexão metalinguística sobre a produção escrita precisa ser, no mínimo, objeto de mais pesquisas, que deverão problematizar, inclusive, o contexto de produção. Como destaca Paris (2002), a perspectiva funcional da metacognição é necessariamente situada, ou seja, "a metacognição não pode ser removida do contexto e avaliada ou estudada independentemente da tarefa e do propósito" (p. 115, tradução nossa). Assim, é preciso considerar que os indivíduos poderão atuar mais metalinguisticamente em algumas situações do que em outras, porque diferentes contextos de uso da linguagem podem prover mais ou menos estímulo para a atividade metalinguística. Uma pessoa pode realizar, por exemplo, mais reflexões metalinguísticas ao escrever um currículo para uma empresa onde deseja trabalhar do que ao escrever mais uma redação para o professor.

Não obstante, é válido observar que, embora os estudantes não tenham se engajado satisfatoriamente na resolução das atividades, eles construíram algum conhecimento relacionado à organização tópica durante as aulas. Posto isso, impõe-se a seguinte indagação: se os alunos construíram conhecimentos sobre estrutura tópica e estratégias de escrita durante a aula, por que não os empregaram?

A análise das produções textuais dos alunos permitiu deduzir que a atividade autorregulatória durante a segunda produção foi escassa. Nesse sentido, os dados sugerem que a construção de conhecimento metacognitivo sobre a escrita e de conhecimento metalinguístico não garante a aplicação deliberada de tais conhecimentos durante a realização de alguma atividade de escrita. Em outras palavras: possuir conhecimento metacognitivo, embora seja condição necessária, não é condição suficiente para o seu emprego na prática, o que está ligado à regulação metacognitiva.

Diversos pesquisadores têm destacado que o desempenho autorregulatório é muito dependente de fatores motivacionais. Ou seja, os redatores podem dispor de estratégias, mas não as empregar durante a escrita, se acreditarem que elas não são eficientes ou se acharem que os resultados não valem o esforço. Além disso, como os estudantes não realizaram as atividades propostas na UD com o engajamento cognitivo necessário, pode-se concluir que eles não exercitaram a regulação metalinguística sobre o planejamento, a produção e a revisão da organização tópica dos parágrafos. Isso sugere que, embora o conhecimento metaestratégico seja relevante para ajustar o desempenho, a regulação metacognitiva está mais ligada à experiência que se adquire com a prática do que ao acúmulo de conhecimento metacognitivo.

Também convém reconhecer que não se desenvolve um comportamento metacognitivo amadurecido num curto período de tempo. $\mathrm{Na}$ verdade, o desenvolvimento da atividade metacognitiva requer treinamento e prática constantes. A abundante literatura disponível - lamentavelmente a maior parte dela não está traduzida para o português - é unânime ao destacar os benefícios da aplicação das descobertas da área da Metacognição ao ensino. Portanto, o desenvolvimento metacognitivo deve fazer parte de qualquer programa educacional que vise à autonomia do aprendiz, visto como 
uma pessoa capaz de gerenciar seus objetivos e processos de aprendizagem. No caso específico das aulas de língua, o objetivo deveria ser desenvolver a consciência metalinguística, com vistas a formar um usuário autônomo do seu idioma, especialmente no que tange à linguagem escrita.

Quanto à experiência e aos desafios, é válido observar que essa metodologia de ensino de produção textual rompe com a percepção de que existe um significado pronto e exterior, a ser assimilado pelos alunos. Um exemplo disso é que frequentemente não há uma "resposta correta" para as atividades, mas sim um exercício de reflexão e de (re)construção do conhecimento. Isso é especialmente observável nas atividades que solicitam o planejamento, a produção, a avaliação e a reformulação de textos. Todas essas operações dependem dos objetivos, planos e conhecimentos sobre língua e sobre escrita dominados pelos aprendizes. Essa situação pode causar certo desconforto aos professores que prefiram a segurança de um "gabarito" e pode causar desconfiança nos estudantes que esperam que o material didático e o professor forneçam a "resposta correta" para as atividades. Assim, essa metodologia, em diversas situações, requer alunos e professores abertos ao debate e à construção do conhecimento no contexto da sala de aula.

Tendo-se apresentado e discutido os resultados, a próxima seção traz as considerações finais.

\section{Considerações finais}

A constatação de que os alunos não se engajaram na realização das atividades formuladas na UD põe duas perspectivas de pesquisa futuras. Uma delas seria reaplicar a UD a alunos com motivação suficiente para realizar todas as atividades. A outra seria remodelar a UD e a sua aplicação para promover a atribuição de valoração positiva às atividades da UD e à escrita no ambiente escolar. Seguindo as sugestões dos próprios alunos, isso pode ser feito com a inclusão de atividades lúdicas e o uso de recursos tecnológicos. Nesse sentido, aventa-se como uma boa estratégia a "gameficação" das lições, a fim de motivar o engajamento dos aprendizes e, assim, facilitar o processo de aprendizagem. Não obstante, é válido notar também que não se desconstroem, com uma intervenção de dois meses de duração, crenças sobre valoração e afetos negativos construídos ao longo da vida escolar.

Naturalmente, esta pesquisa representa apenas uma pequena contribuição para um ensino comprometido com o desenvolvimento metalinguístico. Muito ainda precisa ser pensado para que se tenha um ensino que considere os processos de construção de conhecimento e as experiências dos aprendizes. Os limites da investigação revelaram alguns pontos a serem investigados. Um deles é como abordar didaticamente o desenvolvimento da reflexão metatextual sobre a organização tópica da globalidade do texto, sobretudo naqueles mais complexos, considerando-se a limitação da memória de trabalho. O principal desafio identificado pela fase experimental consiste em agregar, à metodologia de ensino focada no desenvolvimento metacognitivo, o estímulo da motivação para escrever em conjunto com o desenvolvimento da reflexão metalinguística. Oferecer materiais didáticos que desenvolvam as capacidades com esse fim é parte importante da agenda de pesquisas em ensino.

A ponderação que se faz ao fim de todo esse processo é que o caminho do desenvolvimento metacognitivo e metalinguístico não deve ser abandonado. $\mathrm{Na}$ verdade, o caminho precisa ser percorrido muitas mais vezes, de preferência desde o início, quando os alunos dão os primeiros passos dentro da escola. Se o ensino de língua 
como produto não vem dando bons resultados, é preciso haver mais pesquisas para subsidiar mais propostas de intervenção no ensino que foquem no processo. E, seguramente, os estudos das áreas da Metacognição e do Desenvolvimento Metalinguístico oferecem uma fundamentação conceitual bastante profícua nesse sentido.

\section{Referências}

BROWN, G.; YULE, G. Discourse analysis. Cambridge: Cambridge University Press, 1983.

BRUNING, R.; KAUFFMAN, D. Self-efficacy beliefs and motivation in writing development. In: MacARTHUR, C.; GRAHAM, S.; FITZGERALD, J. (Ed.) Handbook of writing research: second Edition. New York: Guilford, 2016, p. 160-173.

CAMPS, A.; MILIAN, M. Metalinguistic activity in learning to write: an introduction. In: CAMPS, A.; MILIAN, M. (Ed.). Metalinguistic activity in learning to write. Amsterdam: Amsterdam University Press, 2000, p. 01-28.

DOOLEY, R.; LEVINSOHN, S. Analyzing discourse: a manual of basic concepts. Dallas, Texas: SIL International, 2001.

EGGINS, S. An introduction to systemic functional linguistics. 2nd ed.Continuum: New York / London, 2004.

FERREIRA, A.; SPINILLO, A. Desenvolvendo a habilidade de produção de textos em crianças a partir da consciência metatextual. In: MALUF, M. (Org.). Metalinguagem e aquisição da escrita. São Paulo: Casa do Psicólogo, 2003, p. 119-148.

FIGUEIREDO, L. A redação pelo parágrafo. Brasília: Universidade de Brasília, 1999.

FLAVELL, J. Metacognition and cognitive monitoring: a new area of cognitivedevelopmental inquiry. American psychologist. vol. 34. n. 10, p. 906-911, 1979.

GARCIA, O. Comunicação em prosa moderna: aprenda a escrever, aprendendo a pensar. 24. ed. Rio de Janeiro: FGV, 2004 [1967].

GERHARDT, A. As identidades situadas, os documentos curriculares e os caminhos abertos para o ensino de língua portuguesa no Brasil. In: GERHARDT, A.; AMORIM, M.; CARVALHO, A. (Org.). Linguística aplicada e ensino: língua e literatura. Campinas, SP: Pontes Editores, 2013, p. 77-113.

GERHARDT, A. O conhecimento metalinguístico, os enquadramentos da construção dos significados nos textos e o ensino de língua portuguesa. Alfa. n. 59. v. 2. São Paulo: UNESP, 2015. p. 231-253.

GERHARDT, A. Ensino de gramática e desenvolvimento metalinguístico: teorias, reflexões e exercícios. Campinas, SP: Pontes, 2016. 
GOMBERT, J. Metalinguistic development. New York, London: HarversterWheatsheaf, 1992.

GOUTSOS, D. Modeling discourse topic: sequential relations and strategies in expository text. Ablex: Nerwood, New Jersey, 1997.

HACKER, D.; KEENER, M.; KIRCHER, J. Writing is applied metacognition. In: HACKER, D., DUNLOSKY, J., GRAESSER, A. (Ed.). Handbook of metacognition in education. New York: Routledge, 2009, p. 154-172.

HAYES, J.; FLOWER, L. Identifying the organization of writing processes. In: GREGG, L.; STEINBERG, E. (Ed.). Cognitive processes in writing. Hillsdale, NJ: Lawrence Erlbaum Associates, 1980, p. 03-30.

HAYES, J. A new framework for understanding cognition and affect in writing. In: LEVY, C.; RANSDELL, S. (Ed.). The science of writing: theories, methods, individual differences, and applications. Mahwah, NJ: Erlbaum, 1996, p. 01-27.

HIDI, S.; BOSCOLO, P. (Ed.). Writing and motivation. Amsterdam: Elsevier, 2007.

KELLOGG, R. The psychology of writing. New York: Oxford University Press, 1994.

LAUTAMATTI, L. Observations on the development of the topic in simplified discourse. In: ENKVIST, N.; KOHONEN, V. (Ed.). Text linguistics, cognitive learning and language teaching. Helsinki: Akateeminen kirjakauppa, 1978, p. 71-104.

LIBERATO, Y.; FULGÊNCIO, L. É possível facilitar a leitura: um guia para escrever claro. São Paulo: Contexto, 2007.

MacARTHUR, C.; GRAHAM, S. Writing research from a cognitive perspective. In: MacARTHUR, C.; GRAHAM, S.; FITZGERALD, J. (Ed.) Handbook of writing research: second edition. New York: Guilford, 2016, p. 24-40.

MARTIN, J.; ROSE, D. Working with discourse: meaning beyond the clause. 2nd ed. New York: Continuum, 2007.

McCORMICK, C. Metacognition and learning. In: REYNOLDS, W.; MILLER, G. (Ed.). Handbook of psychology: educational psychology. vol. 7. Hoboken, New Jersey: John Wiley \& Sons, 2003, p. 79-102.

McCUTCHEN, D.; TESKE, P.; BANKSTON, C. Writing and cognition: implications of the cognitive architecture for learning to write and writing to learn. In: BAZERMAN, C. (Ed.). Handbook of research on writing: history, society, school, individual, text. New York: Taylor \& Francis Group, 2008, p. 554-578.

METCALFE, J. Evolution of metacognition. In: DUNLOSKY, J.; BJORK, R. (Ed.). Handbook of metamemory and memory. New York / Hove: Psychology, 2008, p. 29-46. 
NELSON, T.; NARENS, L. Metamemory: a theoretical framework and new findings. In: BOWER, G. (Ed.) The psychology of learning and motivation: advances in research and theory. vol. 26. Academic Press, 1990, p. 125-169.

NELSON, T.; NARENS, L. Why investigate metacognition? In: METCALFE, J.; SHIMAMURA, A. (Ed.). Metacognition: knowing about knowing. Cambridge, MA: MIT Press, 1994, p. 01-25.

PÉCORA, A. Problemas de redação. 5. ed. São Paulo: Martins Fontes, 1999 [1983].

PEREIRA, L. Produção de texto e desenvolvimento metalinguístico: por uma reescrita como escrita. Rio de Janeiro, 2017. 122f. Dissertação (Mestrado em Letras Vernáculas) - Faculdade de Letras, Universidade Federal do Rio de Janeiro.

PARIS, S. When is metacognition helpful, debilitating, or benign? In: CHAMBRES, P.; IZAUTEM, M.; MARESCAUX, P. (Ed.). Metacognition: process, function and use. Boston: Kluwer, 2002, p. 105-120.

PINTRICH, P. Motivation and classroom learning. In: REYNOLDS, W.; MILLER, G. (Eds.). Handbook of psychology: educational psychology. vol. 7. Hoboken, New Jersey: John Wiley \& Sons, 2003, p. 103-122.

RAVID, D.; TOLCHINSKY, L. Developing linguistic literacy: a comprehensive model. Journal of child language, n. 29, p. 417-447, mai. 2002.

SCARDAMALIA, M.; BEREITER, C. Writing. In: DILLON, R.; STERNBERG, R. (Ed.). Cognition and instruction. San Diego, California: Academic Press, 1986, p. 5981.

SCHWARTZ, B.; PERFECT, T. Introduction: toward an applied metacognition. In: PERFECT, T.; SCHWARTZ, B. (Ed.). Applied metacognition. Cambridge: Cambridge University, 2002, p. 01-11.

SITKO, B. Knowing how to write: metacognition and writing instruction. In: HACKER, D.; DUNLOSKY, J.; GRAESSER, A. (Ed.). Metacognition in educational theory and practice. Mahwah, NJ: Erlbaum, 1998, p. 93-115.

SOARES, M.; CAMPOS, E. Técnica de redação: as articulações linguísticas de pensamento. Rio de Janeiro: Ao Livro Técnico, 1978.

SPINILLO, A.; SIMÕES, P. O desenvolvimento da consciência metatextual em crianças: questões conceituais, metodológicas e resultados de pesquisas. Psicologia: reflexão e crítica, vol. 16. n. 3, p. 537-546, 2003.

SPINILlO, A. A consciência metatextual. In: MOTA, M. (Org.). Desenvolvimento metalinguístico: questões contemporâneas. São Paulo: Casa do Psicólogo, 2009, p. $77-$ 113. 
TORRANCE, M.; GALBRAITH, D. The processing demands of writing. In: MacARTHUR, C.; GRAHAM, S.; FITZGERALD, J. (Ed.) Handbook of writing research. New York: The Guilford Press, 2006, p. 67-80.

VAL, M. Redação e textualidade. 2. ed. São Paulo: Martins Fontes, 1999.

VAN OVERSCHELDE, J. Metacognition: knowing about knowing. In: DUNLOSKY, J.; BJORK, R. (Ed.). Handbook of metamemory and memory. New York / Hove: Psychology, 2008, p. 47-71.

ZIMMERMAN, B.; KITSANTAS, A. A writer's discipline: the development of selfregulatory skill. In: HIDI, S.; BOSCOLO, P. (Ed.). Writing and motivation. Amsterdam: Elsevier, 2007, p. 51-69.

ZIMMERMAN, B.; RISEMBERG, R. Becoming a self-regulated writer: a social cognitive perspective. Contemporary Educational Psychology, n. 22, p. 73-101, 1997.

Recebido em 22 de novembro de 2019

Aceito em 21 de abril de 2020 